\title{
Results of a CIE Detector Response Intercomparison $^{1}$
} Volume 95
This CIE Research Note was pre-
pared for CIE Technical Committee TC 2-06 by

\section{Douglas B. Thomas and Edward F. Zalewski ${ }^{2}$}

National Institute of Standards and Technology, Gaithersburg, MD 20899
Number 5

September-October 1990

\begin{abstract}
A total of fifteen laboratories participated in the CIE detector response intercomparison which was designed to assess the level of agreement among participating laboratories in the absolute measurement (with respect to SI) of photodetector response in the visible spectral region. Most participants were either commercial laboratories or university laboratories with the National Institute of Standards and Technology (NIST) serving as the host laboratory. Each laboratory determined the absolute response of each of two silicon photodi-
\end{abstract}

ode radiometers which were designed for the intercomparison by NIST. Approximately two-thirds of the laboratories reported response values which agreed with the NIST values to within $\pm 1.0 \%$ at the two wavelengths of 488 and $633 \mathrm{~nm}^{3}$

Key words: laboratory evaluation; laser; optical radiation; photodiode; spectral response.

Accepted: August 6, 1990

\section{Introduction}

This report provides the final results of a detector response intercomparison under the aegis of CIE Technical Committee TC 2-06 on Absolute Spectral Responsivity of Detectors. Members of the Technical Committee are listed in Appendix B of this report.

The primary purpose of the intercomparison was to assess the level of agreement among participating laboratories in the absolute measurement (with respect to $\mathrm{SI}$ ) of photodetector response (A/W) in the visible spectral region. The method chosen to accomplish this is to have these laboratories measure the absolute response of selected radiometers

\footnotetext{
${ }^{1}$ A CIE (Commission Internationale de l'Eclairage or International Commission on Illumination) research note. CIE headquarters in Vienna, Austria.

${ }^{2}$ Present address: Hughes Danbury Optical Systems, 100 Wooster Heights Road, Danbury, CT 06810.

${ }^{3}$ Abstracts in French and German are given in Appendix A.
}

at two specific wavelengths near each end of the visible spectrum. The wavelengths selected are those of the helium-neon laser $(632.8 \mathrm{~nm})$ and the argon ion laser $(488.0 \mathrm{~nm})$.

The intercomparison was implemented on the basis of the National Institute of Standards and Technology (NIST) serving as the host laboratory and providing (a) the radiometers to be used in the intercomparison, (b) instructions to participating laboratories in the use of the radiometers in absolute response measurements, and (c) data analysis and a report of the results of the intercomparison.

The intercomparison was conducted in two stages: (1) intercomparison of U.S. laboratories and (2) intercomparison of laboratories outside of the United States. All participating laboratories except two are either commercial laboratories or university laboratories. The Electrotechnical Laboratory in Ibaraki, Japan and the Van Swinden Laboratory, 
The Netherlands, are national standards laboratories. The intercomparison was planned on the basis that NIST would measure the absolute response of all radiometers before shipment to the participating laboratories and then again after the radiometers were returned. The NIST absolute response value for each radiometer would be the average of the two NIST measurements.

\section{The Radiometers}

The radiometers used in this intercomparison were designed for ruggedness and ease of use and included commercially available silicon photodiodes. Each radiometer consists of a silicon photodiode and amplifier circuit mounted in a cylindrical aluminum housing and an external power supply.

Since it was expected that the majority of the laboratories would make their measurements using lasers, the photodiodes were not protected by a window. However, to protect each photodiode during non-use, the diodes were maintained in sealed compartments.

Two types of detectors were used: $E G \& G^{4}$ model UV-444B PN photodiodes and UDT model UV-100 inversion layer photodiodes. Radiometers PI-17, PI-19, PI-20, and PI-21 have the EG\&G photodiodes while radiometers PI-25 through PI32 have the UDT photodiodes. For the UDT photodiodes, a constant reverse bias voltage (4.5 V) was supplied by lithium batteries within each radiometer. The amplifier in each radiometer has gain settings from $10^{4}$ to $10^{9} \mathrm{~V} / \mathrm{A}$ with accuracies of $\pm 0.03 \%$ except for the $10^{9}$ range where it is $\pm 0.5 \%$.

Each participating U.S. laboratory received two radiometers: one with an EG\&G photodiode and one with a UDT photodiode. The reason for requesting each laboratory to measure two radiometers is two-fold. (1) A second radiometer provides a backup for possible shipping damage and (2) there is a check on measurement repeatability.

After the first stage of the intercomparison was completed involving U.S. laboratories, a decision was made to use only the radiometers with the UDT photodiodes for the intercomparison involv-

\footnotetext{
${ }^{4}$ Certain commerical equipment, instruments, or materials are identified in this paper to specify adequately the experimental procedure. Such identification does not imply reconmendation or endorsement by the National Institute of Standards and Technology or by the CIE, nor does it imply that the materials or equipment identified are necessarily the best available for the purpose.
}

ing laboratories in other countries. This decision was made when it was determined that the EG\&G photodiodes exhibited a small but significant response drift at $488 \mathrm{~nm}$ over long periods of time (see sec. 4).

\section{The Intercomparison}

A total of six U.S. laboratories and nine laboratories in other countries participated in the intercomparison. Each laboratory was asked to complete a questionnaire concerning detailed information about their detector response measurement system and to use standard data forms for reporting their results. Tables 1 and 2 list the U.S. laboratories and the information each submitted about their measurements at 488 and $633 \mathrm{~nm}$. Tables 3 and 4 list the corresponding information for laboratories in other countries. The information submitted covered eight measurement parameters: (1) absolute base (absolute standard(s) used), (2) standard deviation of the measurements, (3) number of measurements per radiometer, (4) type of radiation source used, (5) beam diameter of the source, (6) radiant power level at the radiometer, (7) ambient temperature during measurements, and (8) estimated uncertainty (with respect to SI) of the absolute standards used. Some laboratories used a single silicon photodiode as an absolute (standard) base for their measurements. The absolute response of these photodiodes was determined using the self-calibration method $[1,2]$. Two laboratories made measurements only at $633 \mathrm{~nm}$. Of the fifteen laboratories participating in the intercomparison, five laboratories used lasers as radiation sources at both wavelengths and five used a tungsten lamp/filter/ monochromator system at both wavelengths. The remaining laboratories used various combinations of these sources. Radiant power levels ranged from $0.16 \mu \mathrm{W}$ to $0.7 \mathrm{~mW}$.

The measurement system used at NIST for this intercomparison consists of He-Ne and Argon ion lasers, laser stabilizer, spatial filter, beam splitter, and a silicon photodiode monitor detector. Three UDT QED-200 absolute radiometers [3] were used as base standards. Figure 1 is an illustration of the system components. The NIST procedures for determining the absolute response of the intercomparison radiometers consisted basically of two steps: (1) measuring the ratio of the photocurrent of each UDT QED-200 radiometer to the photocurrent of the monitor detector at a particular laser power setting and (2) measuring the ratio of 
Table 1. Participating U.S. laboratories. Wavelength $=488 \mathrm{~nm}$

\begin{tabular}{|c|c|c|c|c|c|c|}
\hline & LLL & NIST & TEKX & UDT & UAZ & WEST \\
\hline Absolute base & EGG & QED2 & $\begin{array}{l}\text { QED, } \\
\text { UDT }\end{array}$ & QED2 & QED2 & \\
\hline S.D. of measurements & $\begin{array}{l}0.24- \\
0.35 \%\end{array}$ & $0.01 \%$ & $0.11 \%$ & $\begin{array}{l}0.039- \\
1.10 \%\end{array}$ & $\begin{array}{l}0.003- \\
0.018 \%\end{array}$ & \\
\hline No. of meas./Radiometer & 5 & 50 & 3 & 2 & 48 & \\
\hline Radiation source & TLF & ARL & TLM & BEN & TLF & \\
\hline Beam diameter & OFA & $4 \mathrm{~mm}$ & $2 \times 5$ & $1 \times 5$ & $2 \times 3$ & \\
\hline Power level & $\begin{array}{l}3.7 \times 10^{-8} \\
\mathrm{~W} / \mathrm{cm}^{2}\end{array}$ & $0.5 \mathrm{~mW}$ & $0.6 \mu \mathrm{W}$ & $2.0 \mu \mathrm{W}$ & $4.0 \mu \mathrm{W}$ & \\
\hline Ambient temp. $\left({ }^{\circ} \mathrm{C}\right)$ & 22 & $25-26$ & 23.0 & 21.0 & 21.0 & \\
\hline Est. abs. uncertainty & $0.77 \%$ & $0.10 \%$ & $0.17 \%$ & $0.07 \%$ & $0.05 \%$ & \\
\hline
\end{tabular}

LLL_Lawrence Livermore National Laboratory, Livermore, California.

NIST-National Institute of Standards and Technology, Gaithersburg, Maryland (Host Laboratory).

TEKX-Tektronix Corporation, Beaverton, Oregon.

UDT-United Detector Technology, Hawthorne, California.

UAZ-University of Arizona, Tucson, Arizona.

WEST - Westinghouse Electric Corporation, Baltimore, Maryland.

EGG-EG\&G UV-444-BQ Photodiode.

QED-UDT QED-100 Radiometer.

QED2-UDT QED-200 Radiometer.

UDT-UDT UV-100L Photodiode.

TLF-Tungsten lamp/Filter.

ARL-Argon ion laser.

HENE-Helium-neon laser.

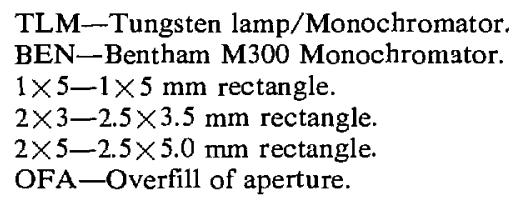

TLM-Tungsten lamp/Monochromator. BEN-Bentham M300 Monochromator.

$1 \times 5-1 \times 5 \mathrm{~mm}$ rectangle.

$2 \times 3-2.5 \times 3.5 \mathrm{~mm}$ rectangle.

$2 \times 5-2.5 \times 5.0 \mathrm{~mm}$ rectangle.

OFA-Overfill of aperture.

Table 2. Participating U.S. laboratories. Wavelength $=633 \mathrm{~nm}$

\begin{tabular}{|c|c|c|c|c|c|c|}
\hline & LLL & NIST & TEKX & UDT & $\overline{\mathrm{UAZ}}$ & WEST \\
\hline Absolute base & $\mathrm{EGG}$ & QED2 & $\begin{array}{l}\text { QED, } \\
\text { UDT }\end{array}$ & QED2 & QED2 & $\begin{array}{l}\text { UDT, } \\
\text { QED2 } \\
\text { EGG }\end{array}$ \\
\hline S.D. of measurements & $0.28 \%$ & $0.012 \%$ & $\begin{array}{l}0.015- \\
0.12 \%\end{array}$ & $\begin{array}{l}0.3- \\
0.4 \%\end{array}$ & $\begin{array}{l}0.018- \\
0.004 \%\end{array}$ & $\begin{array}{l}0.26- \\
0.14 \%\end{array}$ \\
\hline No. of meas./Radiometer & 5 & 50 & 6 & 2 & 64 & 3 \\
\hline Radiation source & TLF & HENE & $\begin{array}{l}\text { TLM, } \\
\text { HENE }\end{array}$ & $\begin{array}{l}\text { BEN, } \\
\text { HENE }\end{array}$ & TLF & HENE \\
\hline Beam diameter & OFA & $4 \mathrm{~mm}$ & $\begin{array}{l}2 \times 5 \\
2.5 \mathrm{~mm}\end{array}$ & $\begin{array}{l}1 \times 5 \\
4 \mathrm{~mm}\end{array}$ & $2 \times 3$ & $2 \mathrm{~mm}$ \\
\hline Power level & $\begin{array}{l}4.9 \times 10^{-8} \\
W / \mathrm{cm}^{2}\end{array}$ & $0.5 \mathrm{~mW}$ & $\begin{array}{l}0.6 \mu \mathrm{W} \\
0.5 \mathrm{~mW}\end{array}$ & $\begin{array}{l}2.0 \mu \mathrm{W} \\
0.5 \mathrm{~mW}\end{array}$ & $11 \mu \mathrm{W}$ & $0.44 \mathrm{~mW}$ \\
\hline Ambient temp. $\left({ }^{\circ} \mathrm{C}\right)$ & 22 & $25-26$ & 23.0 & 21.0 & 21.0 & 20.8 \\
\hline Est. abs. uncertainty & $0.77 \%$ & $0.10 \%$ & $0.17 \%$ & $0.07 \%$ & $0.05 \%$ & $0.05 \%$ \\
\hline
\end{tabular}

LLL-Lawrence Livermore National Laboratory, Livermore California.

NIST-National Institute of Standards and Technology, Gaithersburg, Maryland (Host Laboratory).

TEKX-Tektronix Corporation, Beaverton, Oregon.

UDT-United Detector Technology, Hawthorne, California.

UAZ-University of Arizona, Tucson, Arizona.

WEST-Westinghouse Electric Corporation, Baltimore, Maryland.

EGG-EG\&G UV-444-BQ Photodiode.

QED_UDT QED-100 Radiometer.

QED2-UDT QED-200 Radiometer.

UDT-UDT UV-100L Photodiode.

TLF-Tungsten lamp/Filter.

ARL-Argon ion laser.

TLM-Tungsten lamp/Monochromator.
HENE-Helium-neon laser.

BEN-Bentham M300 Monochromator.

$1 \times 5-1 \times 5 \mathrm{~mm}$ rectangle.

$2 \times 3-2.5 \times 3.5 \mathrm{~mm}$ rectangle.

$2 \times 5-2.5 \times 5.0 \mathrm{~mm}$ rectangle.

OFA-Overfill of aperture. 
Table 3. Participating laboratories in other countries. Wavelength $=488 \mathrm{~nm}$

\begin{tabular}{|c|c|c|c|c|c|c|c|c|c|}
\hline & CIP & ETL & HAM & LCIE & LNE & MAT & KROC & UDI & VSL \\
\hline Absolute base & PSP & HAM2 & & ASP & TSP & HAM2 & HAM3 & EGG & QED2 \\
\hline S.D. of measurements & $\begin{array}{l}0.17- \\
0.21 \%\end{array}$ & $0.04 \%$ & & $0.6 \%$ & $\begin{array}{l}0.11- \\
0.18 \%\end{array}$ & $0.02 \%$ & $0.52 \%$ & $\begin{array}{l}0.12- \\
0.04 \%\end{array}$ & $\begin{array}{l}0.007- \\
0.011 \%\end{array}$ \\
\hline No. of meas./Radiometer & 10 & 4 & & 6 & 27,33 & 10 & 5 & $8-12$ & 75 \\
\hline Radiation source & ARL & TLM & & TLM & TLM & ARL & TLM & ARL & ARL \\
\hline Beam diameter & $4 \mathrm{~mm}$ & $2 \times 3$ & & $5 \mathrm{~mm}$ & $6 \mathrm{~mm}$ & $3 \mathrm{~mm}$ & $7 \mathrm{~mm}$ & $0.6 \mathrm{~mm}$ & $4 \mathrm{~mm}$ \\
\hline Power level & $0.02 \mathrm{~mW}$ & $0.16 \mu \mathrm{W}$ & & $20 \mu W$ & $1.5 \mu \mathrm{W}$ & $0.19 \mathrm{~mW}$ & $\begin{array}{l}2.4 \times 10^{-3} \\
\mathrm{~W} / \mathrm{m}^{2}\end{array}$ & $0.3 \mathrm{~mW}$ & $0.7 \mathrm{~mW}$ \\
\hline Ambient temp. $\left({ }^{\circ} \mathrm{C}\right)$ & 18 & 23 & & 23 & 23 & 25 & 23 & 21 & 23 \\
\hline Est. abs. uncertainty & $0.17 \%$ & $0.07 \%$ & & $0.20 \%$ & $\begin{array}{l}0.11 \\
0.22 \%\end{array}$ & $0.07 \%$ & $0.17 \%$ & $0.50 \%$ & $0.20 \%$ \\
\hline
\end{tabular}

CIP-Central Institute of Physics, Magurele-Bucharest, Romania.

ETL-Electrotechnical Laboratory, Ibaraki, Japan.

HAM-Hamamatsu Photonics K.K., Hamamatsu City, Japan.

LCIE_L.C.I.E., Fontenay-aux-Roses, France.

LNE-Laboratoire National D'Essais, Paris, France.

MAT-Matsushita Electric Industrial Co. Ltd., Moriguchi Osaka, Japan.

KROC-PRC Krochmann GMBH, Berlin, West Germany.

UDI-University College, Dublin, Ireland.

VSL - Van Swinden Laboratory, Delft, The Netherlands.

PSP $-p n$ Silicon photodiode (Romanian).

HAM2-Hamamatsu S 1337 Photodiode.

EGG-EG\&G UV-444B Photodiode.

HAM3-Hamamatsu S 1227 Photodiode.

QED2-UDT QED-200 Radiometer.

ASP-Silicon photodiode.

TSP-Three silicon photodiodes.

ARL-Argon ion laser.

TLM - Tungsten lamp/Monochromator.

$2 \times 3-2 \times 3 \mathrm{~mm}$ rectangle.

Table 4. Participating laboratories in other countries. Wavelength $=633 \mathrm{~nm}$

\begin{tabular}{lcccccccccc}
\hline & CIP & ETL & HAM & LCIE & LNE & MAT & KROC & UDI & VSL \\
\hline Absolute base & PSP & HAM1 & HAM2 & ASP & TSP & HAM2 & HAM3 & EGG & QED2 \\
S.D. of measurements & $0.17-$ & $0.02 \%$ & $0.07-$ & $0.6 \%$ & $0.10-$ & $0.02 \%$ & $0.3-$ & $0.07-$ & $0.02-$ \\
& $0.14 \%$ & & $0.04 \%$ & & $0.08 \%$ & & $0.15 \%$ & $0.08 \%$ & 6 \\
No. of meas./Radiometer & 10 & 3 & 10 & 6 & 21,28 & 10 & 5 & 6 & 75 \\
Radiation source & HENE & HENE & HENE & TLM & TLM & HENE & TLM & HENE & HENE \\
Beam diameter & $4 \mathrm{~mm}$ & $1 \mathrm{~mm}$ & $1.5 \mathrm{~mm}$ & $5 \mathrm{~mm}$ & $6 \mathrm{~mm}$ & $3 \mathrm{~mm}$ & $7 \mathrm{~mm}$ & $0.6 \mathrm{~mm}$ & $4 \mathrm{~mm}$ \\
Power level & $0.1 \mathrm{~mW}$ & $40 \mu \mathrm{W}$ & $25 \mu \mathrm{W}$ & $30 \mu \mathrm{W}$ & $2 \mu \mathrm{W}$ & $0.3 \mathrm{~mW}$ & $1.1 \times 10^{-2}$ & $0.6 \mathrm{~mW}$ & $0.7 \mathrm{~mW}$ \\
& & & & & & & & & & \\
Ambient temp. $\left({ }^{\circ} \mathrm{C}\right)$ & 18 & 23 & 25 & 23 & 23 & 25 & 23 & 18 & 23 \\
Est. abs. uncertainty & $0.17 \%$ & $0.07 \%$ & $0.17 \%$ & $0.20 \%$ & 0.12 & $0.07 \%$ & $0.17 \%$ & $0.08 \%$ & $0.20 \%$ \\
& & & & & $0.09 \%$ & & & &
\end{tabular}

CIP-Central Institute of Physics, Magurele-Bucharest, Romania.

ETL-Electrotechnical Laboratory, Ibaraki, Japan.

HAM-Hamamatsu Photonics K.K., Hamamatsu City, Japan.

LCIE-L.C.I.E., Fontenay-aux-Roses, France.

LNE_Laboratoire National D'Essais, Paris, France.

MAT-Matsushita Electric Industrial Co. Ltd., Moriguchi Osaka, Japan.

KROC-PRC Krochmann GMBH, Berlin, West Germany.

UDI-University College, Dublin, Ireland.

VSL-Van Swinden Laboratory, Delft, The Netherlands.

PSP-pn Silicon photodiode (Romanian).

HAMI-Hamamatsu S 1723 Photodiode.

HAM2-Hamamatsu S 1337 Photodiode.

ASP-Silicon photodiode.

TSP-Three silicon photodiodes.

HAM3-Hamamatsu S 1227 Photodiode.
EGG-EG\&G UV-444B Photodiode. QED2-UDT QED-200 Radiometer.

HENE_Helium-neon laser.

TLM-Tungsten lamp/Monochromator. 


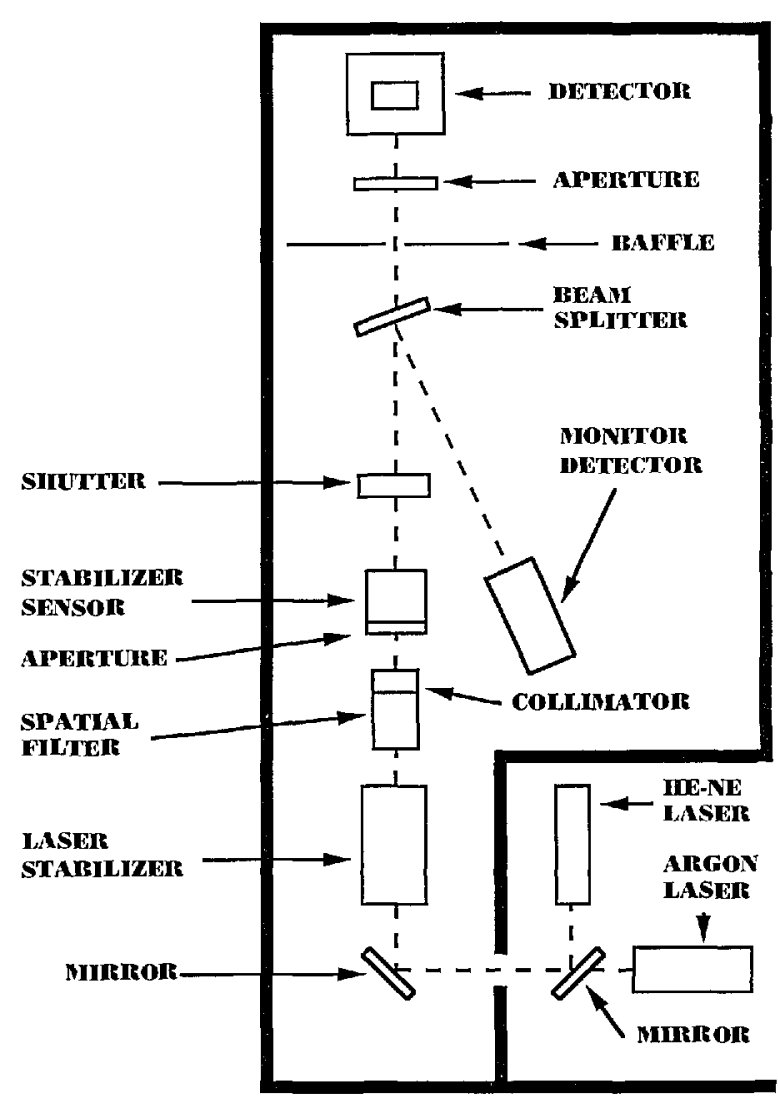

Figure 1. NIST laser based detector calibration facility.

the photocurrent of the intercomparison radiometers to the monitor detector at the same power level in (1). Since the UDT QED-200 radiometers are $100 \%$ quantum efficient (with voltage bias) at the wavelengths and power levels stated, the power (watts) can be accurately measured and the absolute response (amperes/watt) of each of the intercomparison radiometers can be determined. Details concerning the system and the measurement procedure are further described in [4]. The NIST absolute base was compared to other international standards laboratories in a recent detector response intercomparison sponsored by the Consultative Committee on Photometry and Radiometry (CCPR) [5]. In the CCPR intercomparison, the absolute response of a select group of silicon photodiode radiometers were measured by 10 international standards laboratories and also by NIST which served as the host laboratory. The ratios of the NIST response values to the mean of the response values of the other participating laboratories were $1.0011 \pm 0.0035$ and $1.0014 \pm 0.0037$ at the two wavelengths of 488 and $633 \mathrm{~nm}$, respectively.

Since the absolute response values reported by each of the participating laboratories were com- pared to the response values determined at NIST, it was essential for NIST to measure the response of each set of radiometers before it was shipped to the participating laboratory and then measured again after the radiometers were returned. The before and after measurements by NIST were made to determine if any significant changes occurred in the radiometers during shipment.

\section{Data Analysis}

Tables 5 and 6 list the laboratory designations, date of measurement, radiometer descriptions, and absolute responsivities reported by the U.S. laboratories and laboratories in other countries, respectively. Each set of response values for a participating laboratory includes the corresponding before and after values determined by NIST. The NIST value for each radiometer was taken as the average of the before and after respective values. The before and after NIST values indicate that some of the radiometers had undergone a small but significant change in response between shipments to and from the laboratories. For example, at 488 $\mathrm{nm}$, the response value for radiometer PI-20 (laboratory $\mathrm{C}$, table 5) decreased from 0.2814 to 0.2787 over the period $7 / 87$ to $2 / 88$ as measured by NIST. This is a decrease of $0.96 \%$. All ratios reported represent an average of the before and after values.

Since three of the four radiometers with the EG\&G type photodiode showed small but significant decreases in response at $488 \mathrm{~nm}$ over a 7month period, it was decided to use only the radiometers with the UV-100 type photodiodes for the second phase of the intercomparison (foreign laboratories).

Table 7 is a listing of the participating laboratories by code letter, the absolute response values reported by each laboratory, the absolute response values as determined by NIST, and the ratios of the response values.

Figures 2 and 3 are plots of the ratios of the response values $(\mathrm{A} / \mathrm{W})$ determined by each of the participating laboratories to the respective response values (A/W) determined by NIST at 488 and $633 \mathrm{~nm}$. The solid line on each plot is the mean of all the ratios at the respective wavelength and the dashed lines are the standard deviation of the mean. Table 8 is a summary of the standard deviations of the measurements and the estimated uncertainty (with respect to SI) of the absolute standards used by each of the participating laboratories. Also listed are the before/after change in absolute response for each detector as measured by NIST and 
Table 5. U.S. laboratories

\begin{tabular}{|c|c|c|c|c|c|}
\hline \multirow[t]{2}{*}{ Laboratory } & \multirow[t]{2}{*}{ Date } & \multicolumn{2}{|c|}{ Responsivity $(488 \mathrm{~nm})$} & \multicolumn{2}{|c|}{ Responsivity $(633 \mathrm{~nm})$} \\
\hline & & & & PI-20 & PI-25 \\
\hline NIST & $7 / 87$ & & & 0.4551 & 0.4152 \\
\hline LAB A & $7 / 87$ & & & 0.4555 & 0.4154 \\
\hline \multirow[t]{2}{*}{ NIST } & $7 / 87$ & & & 0.4548 & 0.4153 \\
\hline & & PI-21 & PI-27 & PI-21 & PI-27 \\
\hline NIST & $7 / 87$ & 0.2830 & 0.2994 & 0.4550 & 0.4140 \\
\hline LAB B & $9 / 87$ & 0.2857 & 0.2990 & 0.4608 & 0.4208 \\
\hline \multirow[t]{2}{*}{ NIST } & $12 / 87$ & 0.2824 & 0.2986 & 0.4546 & 0.4141 \\
\hline & & PI-20 & PI-25 & PI-20 & PI-25 \\
\hline NIST & $7 / 87$ & 0.2814 & 0.2982 & 0.4548 & 0.4153 \\
\hline LAB C & $9 / 87$ & 0.2802 & 0.2987 & 0.4547 & 0.4151 \\
\hline \multirow[t]{2}{*}{ NIST } & $2 / 88$ & 0.2787 & 0.2984 & 0.4545 & 0.4153 \\
\hline & & PI-19 & PI-28 & PI-19 & PI-28 \\
\hline NIST & $7 / 87$ & 0.2596 & 0.2965 & 0.4472 & 0.4165 \\
\hline LAB D & $11 / 87$ & 0.2570 & 0.3006 & 0.4468 & 0.4168 \\
\hline \multirow[t]{2}{*}{ NIST } & $2 / 88$ & 0.2551 & 0.2969 & 0.4467 & 0.4169 \\
\hline & & PI-17 & PI-30 & PI-17 & PI-30 \\
\hline NIST & $7 / 87$ & 0.2849 & 0.3021 & 0.4580 & 0.4108 \\
\hline LAB E & $12 / 87$ & 0.2799 & 0.3003 & 0.4521 & 0.4027 \\
\hline NIST & $2 / 88$ & 0.2830 & 0.3025 & 0.4576 & 0.4105 \\
\hline
\end{tabular}

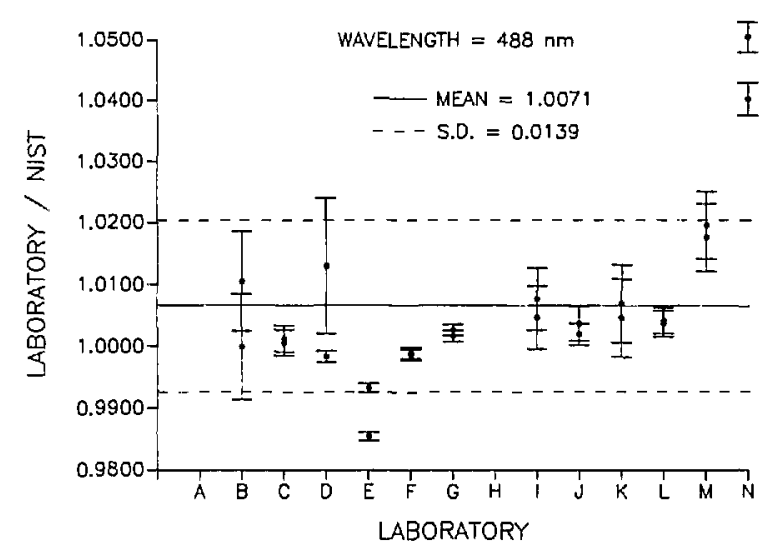

Figure 2. Ratio of the participant laboratory spectral response to that determined by NIST at $488 \mathrm{~nm}$. The error bars indicate the quadrature summation of the measurement and absolute uncertainties of each participant laboratory, the before/after response change for each radiometer, and the NIST measurement and absolute uncertainties. The dashed lines indicate the standard deviation of the ratio values.

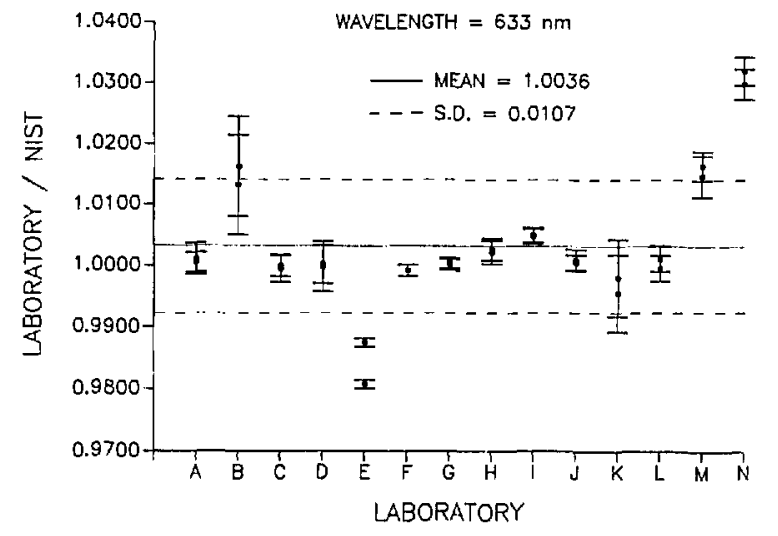

Figure 3. Ratio of the participant laboratory spectral response to that determined by NIST at $633 \mathrm{~nm}$. The error bars indicate the quadrature summation of the measurement and absolute uncertainties of each participant laboratory, the before/after response change for each radiometer, and the NIST measurement and absolute uncertainties. The dashed lines indicate the standard deviation of the ratio values. 
Table 6. Laboratories in other countries

\begin{tabular}{|c|c|c|c|c|c|}
\hline \multirow[t]{2}{*}{ Laboratory } & \multirow[t]{2}{*}{ Date } & \multicolumn{2}{|c|}{ Responsivity (488 nm) } & \multicolumn{2}{|c|}{ Responsivity $(633 \mathrm{~nm})$} \\
\hline & & PI-28 & PI-31 & PI-28 & PI-31 \\
\hline NIST & $2 / 88$ & 0.2969 & 0.3014 & & \\
\hline NIST & $8 / 88$ & & & 0.4169 & 0.4125 \\
\hline LAB F & $10 / 88$ & 0.2964 & 0.3008 & 0.4166 & 0.4124 \\
\hline NIST & $12 / 88$ & & & 0.4169 & 0.4129 \\
\hline \multirow[t]{2}{*}{ NIST } & $1 / 89$ & 0.2967 & 0.3009 & & \\
\hline & & PI-28 & PI-31 & PI-28 & PI-31 \\
\hline NIST & $2 / 88$ & 0.2969 & 0.3014 & & \\
\hline NIST & $8 / 88$ & & & 0.4169 & 0.4125 \\
\hline LAB G & $11 / 88$ & 0.2973 & 0.3019 & 0.4170 & 0.4129 \\
\hline NIST & $12 / 88$ & & & 0.4169 & 0.4129 \\
\hline \multirow[t]{2}{*}{ NIST } & $1 / 89$ & 0.2967 & 0.3009 & & \\
\hline & & & & PI-28 & PI-31 \\
\hline NIST & $8 / 88$ & & & 0.4169 & 0.4125 \\
\hline LAB H & $12 / 88$ & & & 0.4178 & 0.4138 \\
\hline \multirow[t]{2}{*}{ NIST } & $12 / 88$ & & & 0.4169 & 0.4129 \\
\hline & & PI-25 & PI-32 & PI-25 & PI-32 \\
\hline NIST & $2 / 88$ & 0.2983 & 0.2599 & & \\
\hline NIST & $8 / 88$ & & & 0.4153 & 0.4515 \\
\hline LAB I & $11 / 88$ & 0.2999 & 0.2622 & 0.4171 & 0.4538 \\
\hline NIST & $12 / 88$ & & & 0.4148 & 0.4514 \\
\hline \multirow[t]{2}{*}{ NIST } & $1 / 89$ & 0.2987 & 0.2605 & & \\
\hline & & PI-28 & PI-31 & PI-28 & PI-31 \\
\hline NIST & $12 / 88$ & & & 0.4169 & 0.4129 \\
\hline NIST & $1 / 89$ & 0.2967 & 0.3009 & & \\
\hline LAB J & $5 / 89$ & 0.2972 & 0.3020 & 0.4172 & 0.4130 \\
\hline NIST & $8 / 89$ & & & 0.4168 & 0.4127 \\
\hline \multirow[t]{2}{*}{ NIST } & $9 / 89$ & 0.2966 & 0.3009 & & \\
\hline & & PI-28 & PI-31 & PI-28 & PI-31 \\
\hline NIST & $12 / 88$ & & & 0.4169 & 0.4129 \\
\hline NIST & $1 / 89$ & 0.2967 & 0.3009 & & \\
\hline LAB K & $7 / 89$ & 0.2980 & 0.3030 & 0.4160 & 0.4110 \\
\hline NIST & $8 / 89$ & & & 0.4168 & 0.4127 \\
\hline \multirow[t]{2}{*}{ NIST } & $9 / 89$ & 0.2966 & 0.3009 & & \\
\hline & & PI-25 & PI-32 & PI-25 & PI-32 \\
\hline NIST & $12 / 88$ & & & 0.4148 & 0.4514 \\
\hline NIST & $1 / 89$ & 0.2987 & 0.2605 & & \\
\hline LAB L & $6 / 89$ & 0.2995 & 0.2617 & 0.4153 & 0.4511 \\
\hline NIST & $8 / 89$ & & & 0.4148 & 0.4512 \\
\hline \multirow[t]{2}{*}{ NIST } & $9 / 89$ & 0.2982 & 0.2607 & & \\
\hline & & PI-27 & PI-29 & PI-27 & PI-29 \\
\hline NIST & $8 / 88$ & & & 0.4145 & 0.4149 \\
\hline NIST & $2 / 89$ & 0.2989 & 0.2991 & & \\
\hline LAB M & $4 / 89$ & 0.3043 & 0.3049 & 0.4205 & 0.4216 \\
\hline NIST & $8 / 89$ & & & 0.4144 & 0.4147 \\
\hline \multirow[t]{2}{*}{ NIST } & $9 / 89$ & 0.2992 & 0.2988 & & \\
\hline & & PI-26 & PI-30 & PI-26 & PI-30 \\
\hline NIST & $7 / 88$ & 0.2667 & 0.3020 & & \\
\hline NIST & $8 / 88$ & & & 0.4454 & 0.4108 \\
\hline LAB N & $12 / 88$ & 0.2805 & 0.3144 & 0.4583 & 0.4240 \\
\hline NIST & $8 / 89$ & & & 0.4446 & 0.4107 \\
\hline NIST & $9 / 89$ & 0.2672 & 0.3023 & & \\
\hline
\end{tabular}


Table 7. Response ratios

\begin{tabular}{|c|c|c|c|c|c|c|}
\hline \multirow[b]{2}{*}{$\begin{array}{l}\text { Laboratory } \\
\text { (RAD. \#) }\end{array}$} & \multicolumn{3}{|c|}{$488 \mathrm{~nm}$} & \multicolumn{3}{|c|}{$633 \mathrm{~nm}$} \\
\hline & $\begin{array}{l}\text { Resp. } \\
\text { Lab. }\end{array}$ & $\begin{array}{l}\text { Resp. } \\
\text { NIST }\end{array}$ & $\begin{array}{l}\text { Lab./ } \\
\text { NIST }\end{array}$ & $\begin{array}{l}\text { Resp. } \\
\text { Lab. }\end{array}$ & $\begin{array}{l}\text { Resp. } \\
\text { NIST }\end{array}$ & $\begin{array}{l}\text { Lab./ } \\
\text { NIST }\end{array}$ \\
\hline A (PI-20) & & & & 0.4555 & 0.4550 & 1.0011 \\
\hline$A(P I-25)$ & & & & 0.4154 & 0.4152 & 1.0005 \\
\hline B (PI-21) & 0.2857 & 0.2827 & 1.0106 & 0.4608 & 0.4548 & 1.0132 \\
\hline $\mathrm{B}(\mathrm{PI}-27)$ & 0.2990 & 0.2990 & 1.0000 & 0.4208 & 0.4141 & 1.0162 \\
\hline $\mathrm{C}(\mathrm{PI}-20)$ & 0.2802 & 0.2806 & 0.9986 & 0.4547 & 0.4547 & 1.0000 \\
\hline $\mathrm{C}(\mathrm{PI}-25)$ & 0.2987 & 0.2983 & 1.0013 & 0.4151 & 0.4153 & 0.9995 \\
\hline $\mathrm{D}(\mathrm{PI}-19)$ & 0.2570 & 0.2570 & 1.0000 & 0.4468 & 0.4469 & 0.9998 \\
\hline $\mathrm{D}(\mathrm{PI}-28)$ & 0.3006 & 0.2967 & 1.0131 & 0.4168 & 0.4167 & 1.0002 \\
\hline $\mathrm{E}(\mathrm{PI}-17)$ & 0.2799 & 0.2836 & 0.9870 & 0.4521 & 0.4578 & 0.9875 \\
\hline$E(P I-30)$ & 0.3003 & 0.3023 & 0.9934 & 0.4027 & 0.4106 & 0.9808 \\
\hline$F(P I-28)$ & 0.2964 & 0.2968 & 0.9987 & 0.4166 & 0.4169 & 0.9993 \\
\hline$F(P I-31)$ & 0.3008 & 0.3011 & 0.9990 & 0.4124 & 0.4127 & 0.9993 \\
\hline G (PI-28) & 0.2973 & 0.2968 & 1.0017 & 0.4170 & 0.4169 & 1.0002 \\
\hline $\mathrm{G}(\mathrm{PI}-31)$ & 0.3019 & 0.3011 & 1.0027 & 0.4129 & 0.4127 & 1.0005 \\
\hline $\mathrm{H}(\mathrm{PI}-28)$ & & & & 0.4178 & 0.4169 & 1.0022 \\
\hline H (PI-31) & & & & 0.4138 & 0.4127 & 1.0027 \\
\hline I (PI-25) & 0.2999 & 0.2985 & 1.0047 & 0.4171 & 0.4151 & 1.0048 \\
\hline I (PI-32) & 0.2622 & 0.2602 & 1.0077 & 0.4538 & 0.4515 & 1.0051 \\
\hline J (PI-28) & 0.2972 & 0.2966 & 1.0020 & 0.4172 & 0.4168 & 1.0010 \\
\hline $\mathbf{J}(\mathbf{P I}-31)$ & 0.3020 & 0.3009 & 1.0037 & 0.4130 & 0.4128 & 1.0005 \\
\hline $\mathrm{K}(\mathrm{PI}-28)$ & 0.2980 & 0.2966 & 1.0047 & 0.4160 & 0.4168 & 0.9981 \\
\hline $\mathrm{K}(\mathrm{PI}-31)$ & 0.3030 & 0.3009 & 1.0070 & 0.4110 & 0.4128 & 0.9956 \\
\hline L (PI-25) & 0.2995 & 0.2984 & 1.0037 & 0.4153 & 0.4148 & 1.0012 \\
\hline L (PI-32) & 0.2617 & 0.2606 & 1.0042 & 0.4511 & 0.4513 & 0.9996 \\
\hline $\mathrm{M}(\mathrm{PI}-27)$ & 0.3043 & 0.2990 & 1.0177 & 0.4205 & 0.4144 & 1.0147 \\
\hline$M(P I-29)$ & 0.3049 & 0.2990 & 1.0197 & 0.4216 & 0.4148 & 1.0164 \\
\hline$N(P I-26)$ & 0.2805 & 0.2670 & 1.0506 & 0.4583 & 0.4450 & 1.0299 \\
\hline $\mathbf{N}(\mathrm{PI}-30)$ & 0.3144 & 0.3022 & 1.0404 & 0.4240 & 0.4108 & 1.0321 \\
\hline
\end{tabular}

the absolute response ratio uncertainty. The absolute response ratio uncertainty is the quadrature summation of the measurement and absolute uncertainties of each participant laboratory, the before/ after response change for each radiometer, and the NIST measurement and absolute uncertainties. The error bars in figures 2 and 3 indicate the absolute response ratio uncertainty for each laboratory.

\section{Conclusion}

In general, it can be concluded that most of the response values reported by the laboratories were in good agreement with NIST. At $488 \mathrm{~nm}$, the mean of all participating laboratories was $0.71 \%$ higher than the corresponding NIST values with a standard deviation of $1.39 \%$. Similarly, at $633 \mathrm{~nm}$, the mean of all laboratory values was higher than 
Table 8. Summary of uncertainties

\begin{tabular}{|c|c|c|c|c|}
\hline Laboratory & $\begin{array}{c}\text { Measurement } \\
\text { standard } \\
\text { deviation } \\
\text { (1 sigma) }\end{array}$ & $\begin{array}{c}\text { Absolute } \\
\text { uncertainty } \\
\text { (1 sigma) }\end{array}$ & $\begin{array}{c}\text { Before/After } \\
\text { response } \\
\text { change } \\
(\% / 100)\end{array}$ & $\begin{array}{c}\text { Ratio } \\
\text { uncertainty } \\
\text { ( } 1 \text { sigma) }\end{array}$ \\
\hline \multicolumn{5}{|c|}{$488 \mathrm{~nm}$} \\
\hline \multirow[t]{2}{*}{ LLL } & 0.0024 & 0.0077 & 0.0021 & 0.0084 \\
\hline & 0.0035 & 0.0077 & 0.0027 & 0.0089 \\
\hline \multirow{2}{*}{ N1ST } & 0.0001 & 0.0010 & & \\
\hline & 0.0001 & 0.0010 & & \\
\hline \multirow[t]{2}{*}{ TEKX } & 0.0011 & 0.0017 & 0.0096 & 0.0099 \\
\hline & 0.0011 & 0.0017 & 0.0007 & 0.0024 \\
\hline \multirow[t]{2}{*}{ UDT } & 0.00039 & 0.0007 & 0.0175 & 0.0175 \\
\hline & 0.0110 & 0.0007 & 0.0013 & 0.0111 \\
\hline \multirow[t]{2}{*}{ UAZ } & 0.00003 & 0.0005 & 0.0067 & 0.0068 \\
\hline & 0.00018 & 0.0005 & 0.0013 & 0.0017 \\
\hline \multirow[t]{2}{*}{ CIP } & 0.0017 & 0.0017 & 0.0019 & 0.0032 \\
\hline & 0.0021 & 0.0017 & 0.0010 & 0.0031 \\
\hline \multirow{2}{*}{ ETL } & 0.0004 & 0.0007 & 0.0007 & 0.0015 \\
\hline & 0.0004 & 0.0007 & 0.0017 & 0.0021 \\
\hline \multirow[t]{2}{*}{ LCIE } & 0.0060 & 0.0020 & 0.0003 & 0.0064 \\
\hline & 0.0060 & 0.0020 & 0.0000 & 0.0064 \\
\hline \multirow[t]{2}{*}{ LNE } & 0.0011 & 0.0011 & 0.0003 & 0.0019 \\
\hline & 0.0018 & 0.0022 & 0.0000 & 0.0030 \\
\hline \multirow[t]{2}{*}{ MAT } & 0.0002 & 0.0007 & 0.0007 & 0.0014 \\
\hline & 0.0002 & 0.0007 & 0.0017 & 0.0021 \\
\hline \multirow[t]{2}{*}{ KROC } & 0.0052 & 0.0017 & 0.0010 & 0.0057 \\
\hline & 0.0052 & 0.0017 & 0.0010 & 0.0057 \\
\hline \multirow[t]{2}{*}{ UDI } & 0.0012 & 0.0050 & 0.0013 & 0.0054 \\
\hline & 0.0004 & 0.0050 & 0.0023 & 0.0056 \\
\hline \multirow[t]{2}{*}{ VSL } & 0.00007 & 0.0020 & 0.0017 & 0.0028 \\
\hline & 0.00011 & 0.0020 & 0.0008 & 0.0024 \\
\hline \multicolumn{5}{|c|}{$633 \mathrm{~nm}$} \\
\hline \multirow[t]{2}{*}{ LLL } & 0.0028 & 0.0077 & 0.0009 & 0.0083 \\
\hline & 0.0028 & 0.0077 & 0.0002 & 0.0083 \\
\hline \multirow{2}{*}{ NIST } & 0.00012 & 0.0010 & & \\
\hline & 0.00012 & 0.0010 & & \\
\hline TEKX & 0.00015 & 0.0017 & 0.0007 & 0.0021 \\
\hline & 0.0012 & 0.0017 & 0.0000 & 0.0023 \\
\hline UDT & 0.0040 & 0.0007 & 0.0011 & 0.0043 \\
\hline & 0.0030 & 0.0007 & 0.0010 & 0.0034 \\
\hline UAZ & 0.00018 & 0.0005 & 0.0009 & 0.0014 \\
\hline & 0.00004 & 0.0005 & 0.0007 & 0.0013 \\
\hline WEST & 0.0026 & 0.0005 & 0.0007 & 0.0029 \\
\hline & 0.0014 & 0.0005 & 0.0002 & 0.0018 \\
\hline CIP & 0.0017 & 0.0017 & 0.0018 & 0.0032 \\
\hline & 0.0014 & 0.0017 & 0.0002 & 0.0024 \\
\hline ETL & 0.0002 & 0.0007 & 0.0000 & 0.0012 \\
\hline & 0.0002 & 0.0007 & 0.0010 & 0.0016 \\
\hline HAM & 0.0007 & 0.0017 & 0.0000 & 0.0021 \\
\hline & 0.0004 & 0.0017 & 0.0010 & 0.0022 \\
\hline LCIE & 0.0060 & 0.0020 & 0.0002 & 0.0064 \\
\hline & 0.0060 & 0.0020 & 0.0005 & 0.0064 \\
\hline LNE & 0.0010 & 0.0012 & 0.0002 & 0.0019 \\
\hline & 0.0008 & 0.0009 & 0.0005 & 0.0016 \\
\hline MAT & 0.0002 & 0.0007 & 0.0000 & 0.0012 \\
\hline & 0.0002 & 0.0007 & 0.0010 & 0.0016 \\
\hline KROC & 0.0030 & 0.0017 & 0.0002 & 0.0036 \\
\hline & 0.0015 & 0.0017 & 0.0005 & 0.0025 \\
\hline UDI & 0.0007 & 0.0008 & 0.0012 & 0.0019 \\
\hline & 0.0008 & 0.0008 & 0.0002 & 0.0015 \\
\hline VSL & 0.0002 & 0.0020 & 0.0000 & 0.0022 \\
\hline & 0.0002 & 0.0020 & 0.0005 & 0.0023 \\
\hline
\end{tabular}


the NIST values by $0.36 \%$ with a standard deviation of $1.07 \%$. All laboratories participating in this intercomparison (except laboratory $\mathrm{N}$ ) reported values at both wavelengths within $\pm 2.0 \%$ of the NIST values and nine of the 14 laboratories reported values at both wavelengths within $\pm 1.0 \%$ of the NIST values. This can be considered good agreement among the laboratories when one considers the variety of sources, procedures, and testing environments involved in this intercomparison.

\section{Appendix A}

Resumé

Quinze laboratoires situes tant aux Etats-Unis que dans d'autres pays du monde entier ont pris part, dans le cadre de la CIE, a une comparaison de mesures de sensibilite de detecteurs qui avait pour but de determiner le niveau d'accord existant entre les laboratoires participants, pour la mesure de la sensibilite absolue (par rapport au SI) des photodetecteurs dans le domaine visible. La plupart des particpants etaient des laboratoires industriels ou des laboratoires universitaires. Le National Institute of Standards and Technology (NIST) jouait le role de laboratoire pilote. Chaque laboratoire a determine la sensibilite absolute de deux radiometres equipes de photodiodes au silicium, et specialement realises pour cette comparaison par le NIST. Les resultats fournis par environ les $2 / 3$ des laboratoires sont en accord avec ceux du NIST dans la limite d'incertitude de $\pm 1 \%$ pour les longueurs d'onde de 488 et $633 \mathrm{~nm}$.

\section{Zusammenfassung}

Insqesamt fuenfzehn Laboratorien haben an CIE Vergleichsmessungen von optischen Strahlungsempfaengern teilgenommen. Der Vergleich bezweckte die Uebereinstimmung unter den teilnehmenden Laboratorien in der Absolutmessung (relativ zu SI Einheiten) der Empfindlichkeit von Halbleiter-Empfaengern im sichtbaren Spektralgebiet zu bestimmen. Die Mehrzahl der Teilnehmer waren Industrie- oder Universitaetslaboratorien. Das U.S. National Institute of Standards and Technology (NIST) war das Zentrallaboratorium. Jedes Labor bestimmte die absolute Empfindlichkeit von je zwei speziell fuer den Vargleich entwickelten NIST Radiometern mit Silizium-Photodioden. Ungefaehr zwei Drittel der von den einzelnen Laboratorien gemessenen
Empflichkeiten fielen innerhalb $\pm 1 \%$ der NIST Werte bei 488 und $633 \mathrm{~nm}$.

\section{Appendix B}

The following is a listing of the members of CIE Technical Committee TC 2-06 on Absolute Spectral Responsivity of Detectors. An asterisk (*) identifies those members who made the detector measurements for this intercomparison.

* Philip Armatis, Lawrence Livermore National Laboratory, Livermore, California, United States.

* Douglas Thomas, National Institute of Standards and Technology, Gaithersburg, Maryland, United States.

Albert Parr, National Institute of Standards and Technology, Gaithersburg, Maryland, United States.

Edward Zalewski, formerly of the National Institute of Standards and Technology, Gaithersburg, Maryland, United States.

* Ken Futornick, Tektronix Corporation, Beaverton, Oregon, United States.

* Richard Duda, United Detector Technology, Haw thorne, California, United States.

* James Palmer, University of Arizona, Tucson, Arizona, United States.

* Carroll Hughes III, Westinghouse Electric Corporation, Baltimore, Maryland United States.

James Christy, Hughes Electronics Corp., Tucson, Arizona, United States.

Ted Schrode, United States.

Kurt Scott, Atlas Electric Devices Company, Chicago, Illinois, United States.

* Dan Sporea, Central Institute of Physics, Magurele-Bucharest, Romania.

* Yasuo Mishima, Electrotechnical Laboratory, Ibaraki, Japan.

* Keiji Suyama, Hamamatsu Photonics K.K., Hamamatsu City, Japan.

* Yoshihiro Ohno, Matsushita Electric Industrial Co. Ltd., Moriguchi Osaka, Japan.

* B. Jean, Laboratoire Central des Industries Electriques, Fontenay-aux-Roses, France.

* Beatrice Chommeloux, Laboratoire National D'Essais, Paris, France.

Brigitte Mercier, Institute National de Metrologie, Paris, France.

* Gyorgy Czibula, PRC Krochmann GMBH, Berlin, West Germany.

J. Krochmann, PRC Krochmann GMBH, Berlin, West Germany. 
* Eon O'Mongain, University College, Dublin, Ireland.

Maurice Goodman, University College, Dublin, Ireland.

* Jan de Vreede, Van Swinden Laboratory, Delft, The Netherlands.

Pieter Bloembergen, Van Swinden Laboratory, Delft, The Netherlands.

Antonio Corrons, Institute de Optica, Madrid, Spain.

Dominique Crommelynck, Royal Meteorological Institute of Belgium, Brussels, Belgium.

John Moore, National Physical Laboratory, Teddington, United Kingdom.

Juraji Zatkovic, Czechoslovak Institute of Metrology/CSMO, Bratislava, Czechoslovakia.

F. Hengstberger, NPRL/SCIR, Pretoria, South Africa.

Li Tong-Bao, National Institute of Measurement and Testing Technology, Chengdu, China.

\section{References}

[1] Zalewski, E. F., and Geist, J., Appl. Opt. 19, 1214 (1980).

[2] Geist, J., Zalewski, E. F., and Schaefer, R., Appl. Opt. 19, 3795 (1980).

[3] Zalewski, E. F., and Duda, C. Richard, Appl. Opt. 22, 2867 (1983).

[4] Thomas, D. B., and Zalewski, E. F., A Radiometer For Precision Coherent Radiation Measurements, SPIE Tech. Symp. on Aerospace Sensing, Orlando, Florida, March 1989.

[5] Annual Report of the Consultative Committee on Photometry and Radiometry, International Bureau of Weights and Measures, Sevres Cedex, France (1986).

About the authors: Douglas B. Thomas is a physicist in the Radiometric Physics Division in the Center for Radiation Research, which is part of the NIST National Measurements Laboratory. Edward F. Zalewski is a Senior Staff Engineer in the Advanced Developments Laboratory of Hughes Danbury Optical Systems. 